Rev. Ter. Ocup. Univ. São Paulo, v. 23, n. 3, p. 230-6, set./dez. 2012.

\title{
A terapia ocupacional e o serviço residencial terapêutico no município de Belo Horizonte, MG
}

\author{
The occupational therapy and the therapeutic \\ residences services at Belo Horizonte city, MG
}

\author{
Júlia Coutinho Nunes Castilho
}

CASTILHO, J. C. N. A terapia ocupacional e o serviço residencial terapêutico no município de Belo Horizonte, MG. Rev. Ter. Ocup. Univ. São Paulo, v. 23, n. 3, p. 230-6, set./dez. 2012.

\begin{abstract}
RESUMO: A construção da Política de Saúde Mental de Belo Horizonte teve seu início em 1993, seguindo o movimento da Reforma Psiquiátrica. O primeiro Serviço Residencial Terapêutico foi criado na cidade em 2001, dentro de uma política que objetivava a redução dos leitos psiquiátricos e a criação de serviços substitutivos ao mesmo. Desde então, a prioridade e os esforços dos envolvidos no processo se voltam para a reabilitação psicossocial e a reinserção dos moradores na sociedade. Assim, as funções do terapeuta ocupacional, enquanto supervisor do Serviço Residencial Terapêutico, acompanham os princípios da reabilitação psicossocial e incluem intervenções em espaços reais do cotidiano e em suas áreas de desempenho ocupacional, facilitando o resgate do papel do sujeito agente em seu processo de tratamento, em sua própria vida e escolhas. Busca-se desenvolver habilidades e estratégias para incluir os moradores na sociedade, e reestabelecer suas rotinas fora do hospital onde moraram por tantos anos. O trabalho do terapeuta se dá inicialmente na nova casa do usuário, para depois atingir espaços externos e de circulação social, característica que facilita a intervenção e o alcance dos objetivos.
\end{abstract}

DESCRITORES: Terapia ocupacional; Moradias assistidas; Instituições residenciais; Serviços de reabilitação; Centros de reabilitação; Serviços de Saúde mental; Comunidade terapêutica.

Terapeuta ocupacional no CERSAM (Centro de Referência em Saúde Mental) da Secretaria de Saúde de Belo Horizonte, e professora substituta do departamento de Terapia Ocupacional da UFMG.

Endereço para correspondência: Rua Carlos Gomes, 160. Santo Antônio. CEP: 30350-130. Belo Horizonte, MG. E-mail: ju_castilho@ hotmail.com 


\section{INTRODUÇÃO}

$\mathrm{N}$ o Brasil, no final da década de 70, o movimento da Reforma Psiquiátrica representou uma crítica às instituições asilares e à busca de transformação das propostas de atendimentos em saúde mental. Abriu-se espaço para discussão e elaboração de novas formas mais efetivas de cuidar das pessoas com sofrimento mental, que por tempos estiveram restritas e trancafiadas aos muros das instituições. Com a Reforma, a partir das premissas da reabilitação psicossocial e a criação dos serviços substitutivos às internações psiquiátricas de longa permanência, criaram-se novas formas de cuidado, de busca de cidadania e de vida. (DESVIAT, 1999; MÂNGIA; NICÁCIO, 2001).

Para Saraceno $(1999,2001)$ a reabilitação psicossocial é um conjunto de estratégias que buscam a ampliação das trocas de recursos e de afetos dos sujeitos, além do aumento do poder contratual. Para o autor, não existem as desabilidades ou habilidades em si mesmas, elas se definem no âmbito das redes sociais e das trocas que essas redes impedem ou possibilitam, permitem ou proíbem, incentivam ou esquecem.

Para Saraceno (1998, 2001); Mângia e Nicácio (2001), a reabilitação psicossocial é uma forma privilegiada de atenção à saúde. Enfatizam as formas de assistência que focalizam a criação de mecanismos através dos quais as pessoas com transtornos mentais possam recriar suas vidas, a partir da reconstrução de possibilidades de sua participação direta nos processos do cotidiano e de produção da vida. Busca-se o restabelecimento de um contrato social válido e legitimado dentro dos sistemas de trocas e intercâmbios sociais, gerando uma vida com sentido existencial e social.

Os eixos sobre os quais se apóia o aumento da capacidade contratual das pessoas com sofrimento mental são o habitar, que se ocupa da casa e da apropriação da habitação do espaço vital; a rede social, onde acontecem de fato as trocas sociais vivas; e o trabalho, entendido como processo de articulação do campo dos interesses, das necessidades e dos desejos, meio de sustento e autorealização onde se produzem e trocam mercadorias e valores, provocando a construção de novas redes e novas relações entre sujeitos sociais (SARACENO, 1999).

A abertura de espaços de negociação implica em habitar novos espaços, realizar trocas sociais, materiais e de afeto. Isso significa romper com o isolamento da internação, restituir direitos como o de expressão, a possibilidade de aquisição de objetos pessoais e bens materiais, a participação efetiva no mercado de trabalho e a inserção em grupos na vida coletiva (MOREIRA, 2008).
Dentro do processo da reabilitação acontece a desinstitucionalização e o desmonte dos hospícios, além da desestruturação de saberes sobre a loucura, levando o indivíduo a buscar os Centros de Saúde, nos CAPS (Centros de Atenção Psicossocial) - conhecidos em Belo Horizonte como CERSAMs (Centros de Referência em Saúde Mental), e nos Centros de Convivência.

O sentido da palavra desinstitucionalização é mais amplo do que apenas desospitalização. Para Desviat (1999), desinstitucionalizar é tratar o indivíduo em sua totalidade e existência, considerando-se as suas condições concretas de vida. O enfoque deixa de ser na exclusão social e na violência, para tornar-se criação de possibilidades concretas de sociabilidade, de cidadania e de circulação.

O Serviço Residencial Terapêutico (SRT) surgiu dentro do contexto da Reforma Psiquiátrica e da construção da Política de Saúde Mental no Brasil. Está definido pelo art.1, parágrafo único da Portaria 106/00 como sendo:

"Moradias ou casas inseridas preferencialmente na
comunidade, destinadas a cuidar dos portadores de
transtornos mentais egressos de internações psiquiátricas
de longa permanência, que não possuam suporte social
e laços familiares e que viabilizem sua inserção social".
(BRASIL, 2000).

Segundo o Ministério da Saúde (Brasil, 2004), em 2000 havia 40 Residências Terapêuticas no país, e em 2009 esse número aumentou para 470.

Algumas leis nacionais regulamentam os direitos das pessoas com sofrimento mental, como a Lei Estadual 11.802, de 1995 (no mesmo ano em que Belo Horizonte sediava o II Encontro Nacional da Luta Antimanicomial), posteriormente alterada pela Lei 12.684, de 1997, dispõem sobre a promoção de saúde e reintegração social das pessoas com sofrimento mental. Foram apresentadas os princípios normativos orientadores do redesenho da assistência em saúde mental de Minas Gerais, que, em linhas gerais, indicavam a criação de serviços que garantissem a desospitalização responsável dos portadores de sofrimento mental.

O Programa de Volta para Casa foi criado pela Lei Federal 10.708 de 2003, e é um dos instrumentos mais efetivos para a reintegração social das pessoas com longo histórico de hospitalização. Dispõe sobre a regulamentação do auxílio-reabilitação psicossocial a usuários que tenham permanecido em longas internações psiquiátricas. $\mathrm{O}$ objetivo é contribuir efetivamente para o processo de inserção social dessas pessoas, através do pagamento mensal de um auxílio-reabilitação no valor de $\mathrm{R} \$ 320,00$ aos seus beneficiários. O De Volta para Casa atende ao disposto na 
Lei 10.216, que determina que os pacientes longamente internados ou para os quais se caracteriza a situação de grave dependência institucional, sejam objetos de política específica de alta planejada e reabilitação psicossocial assistida (BRASIL, 2003).

Este artigo busca resgatar parte do percurso da rede de saúde mental de Belo Horizonte, Minas Gerais, destacando o Serviço Residencial Terapêutico (SRT). Também visa discutir as contribuições da Terapia Ocupacional para o SRT, aliando a teoria sobre o tema à prática clínica da autora enquanto supervisora do serviço. A mesma esteve nessa função de supervisão durante três anos, além de ter participado do fechamento de um grande hospital psiquiátrico municipal, abrindo novas Residências Terapêuticas para receber os ex-moradores dessa instituição e acompanhando-os na trajetória de construção de um lar.

\section{A Rede de Belo Horizonte e o Serviço Residencial Terapêutico}

Segundo Nilo et al. (2008) o início da construção da Política de Saúde Mental de Belo Horizonte se deu em 1993, quando passaram a ser implantadas políticas públicas inovadoras após a mudança de gestão, seguindo os preceitos da Reforma Psiquiátrica. Até então, a cidade dispunha somente dos Centros de Saúde com equipes básicas de saúde mental, que atendiam as demandas mais leves, deixando os casos mais graves sob responsabilidade dos hospitais. Contávamos com aproximadamente 2.180 leitos distribuídos em seis hospitais psiquiátricos privados e públicos que tinham convênio com o SUS, sendo que $70 \%$ desses leitos eram ocupados por pacientes provenientes de Belo Horizonte.

Desde 1993 a desinstitucionalização e a reintegração de portadores de sofrimento mental na comunidade têm sido uma das tarefas em que a Prefeitura e a Secretaria de Saúde Municipal vêm se dedicando. Criaram-se novos dispositivos de acolhimento e atendimento:

- CERSAMs (Centros de Referência em Saúde Mental): responsáveis pelo cuidado aos casos graves no momento de crise e de urgência psiquiátrica. São sete unidades distribuídas entre as regionais da cidade, que funcionam dia e noite durante os sete dias da semana, com equipes multiprofissionais;

- Centros de Convivência: em número de 9 , onde se priorizam o convívio, a circulação social e a sociabilidade, os encontros, a descoberta de gostos, habilidades e talentos, através de elementos advindos da cultura;

- Serviço de Urgência Psiquiátrica noturno, anexado a um Hospital Geral, que acolhe, atende, e encaminha no dia seguinte para o CERSAM mais próximo da residência do paciente;

- Incubadora de Empreendimentos Solidários da Saúde Mental: política implantada em 2003, objetivando geração de renda e oportunidade de trabalho aos usuários, que deu origem à ONG Suricato - Associação de Trabalho e Produção Solidária. É gerida pelos próprios usuários que integram quatro grupos de produção nas áreas de marcenaria, culinária, mosaico, moda e vestuário. Além de se responsabilizarem pela produção, os usuários cuidam de uma loja de comercialização dos produtos no centro da cidade;

- Centros de Saúde e suas Equipes de Saúde Mental: 58 no total, que trabalham em parceria com as 578 Equipes de Saúde da Família, tornando mais ampla e efetiva a inserção dos usuários no campo da saúde;

- CERSAM Infantil: atendimento de saúde mental a crianças e adolescentes de até 18 anos de idade. Além do CERSAM, o acompanhamento a essa clientela é feito também pelas equipes de saúde da família e de saúde mental da criança e do adolescente (compostas por psiquiatra infantil, terapeuta ocupacional e fonoaudiólogo), que estão presentes em todos os nove distritos sanitários;

- Serviço Residencial Terapêutico: 25 casas inseridas nos bairros da cidade, que oferecem um lar e possibilitam aos moradores o retorno à sociedade, após muitos anos de internação em manicômios.

Em 2001 foi inaugurada pela Secretaria de Saúde a primeira Residência Terapêutica (RT) do município, com 10 moradores. Logo em seguida, criaram-se mais nove casas em decorrência do fechamento de dois grandes hospitais psiquiátricos privados conveniados com o SUS. Em 2008 iniciou-se o fechamento de mais um hospital, processo do qual a autora participou como supervisora das RTs que receberiam esses moradores. Foram criadas mais 14 RTs para acolher os moradores dessa instituição, e a Secretaria de Saúde Municipal montou uma equipe para acompanhar a transição dos moradores que não seriam recebidos por suas famílias, e sim no SRT.

A princípio, os moradores passaram a sair do hospital para reconhecer a cidade que não viam há anos, indo a parques, ao centro e fazendo outros passeios que significavam tanto para eles. Em um segundo momento, foram conhecer sua nova casa, juntamente com os demais moradores. A partir dessas saídas terapêuticas, do hospital para a cidade e para seu novo lar, os moradores foram se preparando e se fortalecendo para iniciar essa mudança em suas vidas.

Com a chegada à residência, começava então uma fase mais longa do processo de desinstitucionalização e de 
reabilitação, uma vez que eles já estavam fora do hospital, encarando uma casa própria e os desafios de reconstruir a própria vida. Ao recebê-los na casa, a supervisora ajudavaos a equipá-la com os novos utensílios e móveis, orientava a divisão de tarefas domésticas, a divisão dos moradores por quartos, e auxiliava na retomada de funções e tarefas que há anos não eram desenvolvidas, como ir ao banco ou ao supermercado, como lidar com seu dinheiro, limpar a casa, ou simplesmente usar o chuveiro de água quente ou o vaso sanitário.

Atualmente, em 2012, a rede pública de Belo Horizonte conta com 25 Residências Terapêuticas espalhadas pela cidade, que abrigam aproximadamente 200 moradores (NILO et al., 2008).

As RTs de Belo Horizonte são mistas, de complexidade e perfis distintos. Há uma casa na qual residem pessoas com maior grau de dependência para as atividades de vida diária em decorrência de comprometimentos cognitivos e neurológicos; outra casa que abriga somente um morador; ou uma casa ampla e sem escadas onde moram pessoas de idade mais avançada e com dificuldade de locomoção. Enfim, a busca pela casa para alugar depende do perfil e das necessidades de seus futuros moradores. Esse quesito também orienta a atuação do terapeuta ocupacional na casa, mostrando a necessidade de cada um, e guiando as intervenções a serem feitas, sejam elas individuais ou coletivas.

A manutenção destas casas é feita com recursos financeiros que eram anteriormente destinados aos leitos de hospitais psiquiátricos. Para cada morador transferido para uma Residência Terapêutica, um igual número de leitos psiquiátricos é descredenciado do SUS e os recursos financeiros que os mantinham são realocados para a manutenção do SRT. A maioria dos moradores recebe o benefício De Volta Para Casa, que "tem um caráter indenizatório àqueles que, por falta de alternativas, foram submetidos a tratamentos aviltantes e privados de seus direitos básicos de cidadania" (BRASIL, 2004).

O benefício mensal favorece a autonomia e o aprendizado financeiro, já que os moradores passam a administrar seu dinheiro e compram o que precisam para uso próprio. Com a ajuda da terapeuta ocupacional, os moradores vão ao supermercado, à feira, ao shopping, fazem passeios e viagens. Aprendem a cuidar de seu dinheiro e a gastá-lo em uso próprio ou de sua casa. É comum os moradores usarem seu dinheiro em compras de lanches, refrigerante e alimentos, em roupas que há tempo não tinham acesso, na organização de festas de aniversários e outras datas comemorativas, na assinatura de canais de televisão a cabo, ou simplesmente investir o dinheiro em caderneta de poupança . É possível retomar planos futuros e compartilharem sonhos, que há tempo tinham sido abandonados.

As RTs são referenciadas pelos Centros de Saúde, tanto pelas Equipes de Saúde Mental quanto pelas de Saúde da Família, e também pelos Centros de Convivência. Os moradores freqüentam os CERSAMs em momentos pontuais de crise, em que precisam de uma intervenção e de um acompanhamento mais próximo. A proposta é que eles transitem pela cidade e usufruam dos dispositivos da rede de saúde mental de acordo com suas necessidades em cada momento, como qualquer cidadão belorizontino, sendo pessoas com sofrimento mental ou não.

Para Nilo et al. (2008), o Programa de Saúde da Família (PSF) sendo responsável pela clientela psiquiátrica de determinados territórios da cidade, indica a ruptura da negação aos loucos e mostra que devem se valorizar também as queixas clínicas além das questões psiquiátricas, que na maioria das vezes eram negadas. É comum os moradores recém chegados nas RTs, ao iniciarem o acompanhamento com o PSF, descobrirem-se portadores de diabetes, de hipertensão arterial ou de problemas ginecológicos, por exemplo, que nunca tinham sido investigados nos hospitais onde moravam.

\section{A Terapia Ocupacional}

Para Mângia e Nicácio (2001), a Terapia Ocupacional, seguindo novas tendências profissionais, procura trazer para seu campo de reflexão teórico e para suas ações práticas o compromisso com as necessidades objetivas e subjetivas dos sujeitos, a partir de uma visão ampliada de saúde enredada à construção de direitos dos usuários, como saúde, lazer, educação, liberdade de expressão e convívio social. Novos saberes e novas formas de intervenção são construídos, novas relações são estabelecidas entre os terapeutas e usuários, a partir de necessidades cotidianas.

Moreira (2008) também afirma nesse sentido, alegando que a incorporação das estratégias da reabilitação psicossocial redimensionou as práticas dos profissionais, que passaram a trabalhar com a complexidade das ações humanas, que ganham sentido na interação real do sujeito com o seu cotidiano. A prática da profissão engloba intervenções no domicílio, na sociedade, no lazer, na família, entre outros. No Serviço Residencial Terapêutico, o terapeuta ocupacional tem a possibilidade de intervir em todos esses aspectos, ao se colocar ao lado dos moradores, em sua própria casa.

Trabalhar no território inclui os componentes, saberes e forças concretas da comunidade que propõem soluções, 
apresentam demandas e que podem construir objetivos comuns. Significa resgatar os saberes e potencialidades dos recursos da comunidade, construindo coletivamente as soluções, a multiplicidade de trocas entre as pessoas e os cuidados em saúde mental. É a ideia do território como organizador da rede de atenção à saúde mental, que deve orientar as ações de todos os seus equipamentos (NILO et al., 2008). Segundo Benetton e Goubert (2000), o objetivo da Terapia Ocupacional é proporcionar a inserção social de populações marginalizadas, como as pessoas com sofrimento mental.

A criação das casas inaugura um novo cenário para seus moradores, pois a experiência de viver em uma casa e não mais no hospital acentua o protagonismo dos usuários, e abre a possibilidade de serem autores de suas próprias histórias. Oferecem um lar, onde seus moradores se responsabilizam pelo ambiente, por seus pertences, pela rotina e pelas relações. Para isso, além do lar e do ambiente físico, é preciso um profissional que trabalhe com os moradores essas questões, pois após muitos anos de internação, a maioria desses cuidados se perdeu.

Os moradores sentem-se parte atuante na RT, e distribuem entre si as atividades domésticas que devem ser realizadas, como limpeza de banheiros e da casa, manutenção de suas roupas e o preparo da alimentação. Sentem-se responsáveis por suas tarefas e por sua casa, demonstram prazer em fazer o almoço do dia e escolhem o cardápio no momento em que vão realizar as compras na feira. Bezerra (1992) afirma que a reintegração do morador não é uma adaptação a um determinado padrão de normalidade, mas a um "reintegrar-se a si próprio e a uma rede subjetiva", fortalecendo no sujeito o sentimento de "estar no mundo".

A principal preocupação da reabilitação psicossocial é com as transformações que ocorrem na vida do sujeito, e sua forma de se relacionar com o mundo a sua volta e consigo mesmo (BENETTON, 1993/6). Dentro desse movimento de reabilitação é que a atuação do terapeuta, enquanto supervisor de uma RT, mostra seu diferencial através da intervenção no cotidiano, nas áreas de desempenho ocupacional dos moradores e no desenvolvimento de novas habilidades. Para Moreira (2008), o contato constante do terapeuta com os diversos interlocutores (moradores, vizinhos, profissionais da saúde, sociedade) e o reconhecimento das condições objetivas do território (transporte coletivo, equipamentos sociais, condições de moradia, barreiras geográficas e arquitetônicas, lazer, entre outros), passam a constituir novas formas de compreender e lidar com a questão da reabilitação.

Além das funções de reabilitação, o supervisor da
RT deve coordenar a equipe de cuidadores, e se empenhar em questões administrativas, como prestação de contas do repasse feito pela Secretaria de Saúde, prestação de contas do De Volta Para Casa dos moradores à Coordenação de Saúde Mental Municipal, e qualquer outro repasse financeiro feito à casa. Galheigo (2003) sugere que lidar com o cotidiano significa mais do que cuidar da rotina do sujeito, e sim da possibilidade de oferecer a ele a autonomia para contar e fazer a sua própria história, sentindo-se parte do grupo e do coletivo.

A Terapia Ocupacional tem sua ação e sua relevância ao favorecer a organização da rotina dos moradores e da casa, intervindo em áreas de desempenho ocupacional como atividades instrumentais de vida diária, lazer, atividades produtivas e circulação social, em espaços reais de convivência e habitar. Para Benetton (1993/96), em sua ação mediadora, oferece ao sujeito ressignificar seu cotidiano e se reconhecer como protagonista de sua própria história. Promove e facilita as condições do morador em habitar sua própria casa, tendo papel de mediador entre o mundo interno e o mundo externo do morador.

Além disso, cuida do cotidiano dos moradores; de suas singularidades, seus interesses, vontades, e dos papéis que desenvolvem na sociedade, além de atuar como facilitador nas estratégias de resgate do papel do sujeito agente em seu processo de tratamento, de conhecimento, de re-conhecimento, de criação, de re-criação e transformação de seu cotidiano e de sua vida. Para Moreira (2008), tais estratégias apresentam o território comunitário como o espaço privilegiado para a atenção em reabilitação e intervenção da terapia ocupacional.

\section{CONCLUSÃO}

A experiência antimanicomial de Belo Horizonte tem sido rica e única para todos os seus participantes, sejam eles usuários, gestores ou trabalhadores. As RTs, inseridas na comunidade e fora das instituições asilares, permitem uma reaproximação muito rica do corpo, do espaço e do tempo, do uso dos objetos e propiciam a formação de vínculos interpessoais. Criam novas oportunidades sociais na comunidade e melhores condições para lutar contra o preconceito relacionado à loucura.

O terapeuta ocupacional supervisor das RTs atua na coordenação e na organização de seu dia-a-dia, intervindo em espaços reais de moradia, lazer e de circulação social. Coloca-se junto dos moradores para acompanhálos no percurso de saída dos hospitais para sua própria casa, acreditando que, apesar de algumas dificuldades e limitações, eles são capazes de retomar suas atividades, de responder por suas próprias vidas e de retornarem à 
sociedade e às atividades que lhes foram tiradas há tanto tempo.

Um novo cuidar, um cuidar diferenciado leva tanto o terapeuta ocupacional quanto o morador a ultrapassarem barreiras impostas por tantos anos de exclusão e posse de um saber cristalizado. Torna-se prioridade então, tirar o morador da exclusão e reintegrá-lo a uma sociedade, ajudá-lo a se adaptar a uma comunidade, que irá aceitá-lo como cidadão e vizinho no momento em que o mesmo se torna integrante de uma moradia terapêutica.

Cabe aos profissionais divulgar o conhecimento construído, fortalecendo as iniciativas de desinstitucionalização a partir do que vivemos com nossos novos cidadãos: a coragem de ousar, a vontade de ser e viver intensamente a liberdade. A aventura de viver na cidade, de transitar pela rede e descobrir-se cidadão de uma pátria livre, já fizeram novos os gestos e os rostos, os sonhos e os homens que a experimentaram.

CASTILHO, J. C. N. The occupational therapy and the therapeutic residences services at Belo Horizonte city, MG. Rev. Ter. Ocup. Univ. São Paulo, v. 23, n. 3, p. 230-6, set./dez. 2012.

\begin{abstract}
The construction of the Mental Health Policy in Belo Horizonte/MG began in 1993 following the movement of the Psychiatric Reform. The first Residential Therapeutic Service was created in the city in 2001, within a public policy that was aimed at the reduction of psychiatric beds and the creation of alternative services to it. Since then, the priority and efforts of those involved in the process turn to the psychosocial rehabilitation and integration of patients back into society. Thus, the Occupational Therapist's function as a Residential Therapeutic Service supervisor is aligned with the Psychosocial Rehabilitation goals, including intervention in the routine of residents and their areas of occupational performance, facilitating the rescue of the individual role in the process of treatment, his own life and choices. It aims to develop strategies and skills to reintroduce the resident in the society and reestablish their lives outside the hospital. The work of the Occupational Therapist as a supervisor of Therapeutic Residences occurs within actual areas of housing and social movement, a characteristic that facilitates intervention and achieving objectives.
\end{abstract}

KEYWORDS: Occupational therapy; Assisted living facilities; Residential facilities; Rehabilitation services, Rehabilitation centers; Mental health services; Therapeutic community.

\title{
REFERÊNCIAS
}

BENETTON, M. J. Terapia ocupacional e reabilitação psicossocial: uma relação possível? Rev. Ter. Ocup. Univ. São Paulo, v. 4, n. 7, p. $53-58,1993 / 6$.

BENETTON, M. J.; GOUBERT, J. P. Fazemos atividades produção intelectual e valor heurístico em terapia ocupacional. Rev. CETO, São Paulo, v. 5, n. 5, p. 11-15, 2000.

BEZERRA Jr., B. Da verdade à solidariedade: A psicose e os psicóticos. In: BEZERRA Jr, B.; Amarante, P. (Org.). Psiquiatria sem hospício: contribuições ao estudo da reforma psiquiátrica. Rio de Janeiro: Relume-Dumará; 1992. p. 31-37.

BRASIL. Ministério da Saúde. Portaria 106. 11 de fevereiro de 2000. Cria os Serviços Residenciais Terapêuticos em Saúde Mental. Disponível em: < http//www.conselho.saude.gov.br.comissao/ documentos.Decreto-lei106/2000>. Acesso em: 18 jun. 2011.

BRASIL. Ministério da Saúde. Manual do Programa "De Volta para Casa”. Brasília, DF, 2003. Disponível em: <http://bvsms. saude.gov.br/bvs/publicacoes/Manual_PVC.pdf $>$. Acesso em: 30 ago. 2011.

BRASIL. Ministério da Saúde. Secretaria de Atenção à Saúde/DAPE. Saúde mental no SUS: os Centros de Atenção Psicossocial. Brasília, DF, 2004.

DESVIAT, M. A reforma psiquiátrica. Rio de Janeiro: Fiocruz, 1999.

GALHEIGO, S. M. O cotidiano na Terapia Ocupacional: cultura, subjetividade e contexto histórico-social. Rev. Ter. Ocup. Univ. São Paulo, v. 14, n. 3, p. 104-109, 2003.

MÂNGIA, E. F.; NICÁCIO, F. Terapia Ocupacional em saúde mental: tendências principais e desafios contemporâneos. In: DE CARLO, M. M. R. P.; BARTALOTTI, C. Terapia ocupacional 
CAStilho, J. C. N. A terapia ocupacional e o serviço. Rev. Ter. Ocup. Univ. São Paulo, v. 23, n. 3, p. 230-6, set./dez. 2012.

no Brasil: fundamentos e perspectivas. São Paulo: Plexus, 2001. p. $63-80$

MOREIRA, A. B. Terapia Ocupacional: história crítica e abordagens territoriais/comunitárias. Vita et Sanitas, Trindade/ Go, v. 2, n . 2, 2008.

NILO, K, et al. Política de Saúde Mental de Belo Horizonte: O Cotidiano de uma Utopia. Belo Horizonte: Secretaria Municipal de Saúde de Belo Horizonte, 2008.

SARACENO, B. A concepção de reabilitação psicossocial como

Aceito para publicação: 27/11/2012

referencial para as intervenções terapêuticas em saúde mental. Rev. de Ter. Ocup. Univ. São Paulo. V. 9, n. 1, abr/1998, p. 26-31.

SARACENO, B. Libertando identidades: da reabilitação psicossocial à cidadania possível. Rio de Janeiro: TeCorá- Instituto Franco Basaglia; 1999.

SARACENO, B. Reabilitação Psicossocial no Brasil. In: PITTA. A. (org.) Reabilitação Psicossocial no Brasil. 2. ed. São Paulo: HUCITEC, 2001, p.19-26. 